\section{Facharztprüfung zur Erlangung des Facharzttitels FMH für Hämatologie}

Aufgrund des Weiterbildungsprogrammes, welches am 1. Juli 1995 in Kraft gesetzt wurde, ist die Teilnahme an der Facharztprüfung für diejenigen Kandidatinnen und Kandidaten Voraussetzung für die Erlangung des Facharzttitels FMH für Hämatologie, welche ihre Weiterbildung in Hämatologie bis am 30. Juni 1996 nicht abgeschlossen hatten. Es empfiehlt sich, die Facharztprüfung frühestens im letzten Jahr der reglementarischen Weiterbildung abzulegen (Art. 22 WBO).
Ort: Inselspital, Bern

Zeitpunkt: Dienstag, 10. Oktober, und Mittwoch, 11. Oktober 2000

Prüfungsstoff: entspricht Punkt 3 des Weiterbildungsprogrammes vom 1. Juli 1995, publiziert in der Schweizerischen Ärztezeitung Nr. 24/1995 vom 14.6. 1995.

Prüfungsgebühr: Die SGH erhebt eine Prüfungsgebühr von Fr. 750.-.

Anmeldung: Schriftliche Anmeldung an: Sekretariat der SGH, Innerer Giessenweg 37, Postfach 1085, 3110 Münsingen, Tel. 03172207 20, Fax 031722 0722.

Anmeldefrist: 31. Juli 2000

\section{Examen de spécialiste en vue de l'obtention du titre de spécialiste FMH en hématologie}

Conformément au programme de formation postgraduée entré en vigueur le $1^{\text {er }}$ juillet 1995 , la participation à l'examen de spécialiste est une condition requise pour les candidats à l'obtention du titre de spécialiste FMH en hématologie, qui n'avaient pas terminé leur formation postgraduée en hématologie le 30 juin 1996. Il leur est recommandé de passer l'examen de spécialiste au plus tôt durant la dernière année de leur formation postgraduée réglementaire (art. 22 RFP).
Lieu: Hôpital de l'Ile, Berne

Date: Mardi, 10 octobre et mercredi, 11 octobre 2000

Matières d'examen: correspondant au point 3 (exigences) du programme de formation postgraduée du 1er juillet 1995, publié dans le bulletin des médecins suisses au no. 35/1995 du 30.8.1995.

Taxe d'examen: La SSH prélève une participation aux frais de Fr. 750.-.

Inscription: Inscriptions par écrit auprès du secrétariat SSH, Innerer Giessenweg 37, Case postale 1085, 3110 Münsingen, tél. 03172207 20, fax 031 7220722.

Délai d'inscription: 31 juillet 2000 